\title{
Biblioteca Digital de Teses e Dissertações da Universidade Federal do Rio Grande do Norte: uma reflexão acerca de seu papel como meio de preservação da memória ${ }^{1}$
}

\author{
Monise Danielly Pessoa Vila \\ Bibliotecária na Escola de Governo Cardeal Dom Eugênio de Araújo Sales \\ Graduada em Biblioteconomia pela Universidade Federal do Rio Grande do Norte (UFRN) \\ E-mail: monise.danielly@gmail.com \\ Mayane Paulino de Brito e Silva \\ Mestranda em Ciência da Informação pela Universidade Federal da Paraíba (UFPB) \\ Graduada em Biblioteconomia pela Universidade Federal do Rio Grande do Norte (UFRN) \\ E-mail: mayanepaulino.b@gmail.com
}

\section{RESUMO:}

Analisa a importância da preservação da memória através da Biblioteca Digital de Teses e Dissertações (BDTD) da Universidade Federal do Rio Grande do Norte (UFRN). Tem como objetivo geral realizar algumas reflexões a partir de revisão de literatura sobre a BDTD, e como objetivo específico mostrar a importância da BDTD da UFRN para a preservação digital de trabalhos científicos (teses e dissertações). Aborda a importância da memória e da preservação desta em meio digital. Apresenta um breve histórico sobre a BDTD no Brasil e na UFRN. Relata os procedimentos de inserção de trabalhos no sistema eletrônico da BDTD. Utilizou-se como metodologia pesquisas de cunho bibliográfico e em meios eletrônicos, bem como experiências empíricas no contexto da BDTD. Conclui que a memória digital é de suma importância para resguardar todo o material necessário, evitando assim danos que possam por em risco a informação e a memória, tornando esta acessível a toda posteridade, e que a BDTD da UFRN é uma ferramenta essencial para preservação da memória científica da universidade.

Palavras-chave: Preservação da memória. Memória digital. Biblioteca Digital de Teses e Dissertações - UFRN.

\section{ABSTRACT:}

Analyzes the importance of preservation of memory by Biblioteca Digital de Teses $e$ Dissertações (BDTD) of Universidade Federal do Rio Grande do Norte (UFRN). Aims making some observations from the literature review on BDTD and showing the importance of BDTD UFRN for digital preservation of scientific papers (theses and dissertations). Addresses the importance of memory and its preservation in digital media. Presents a brief history of the BDTD in Brazil and UFRN. Reports the works insertion procedures on the electronic system of BDTD. The methodology used was the literature review and empirical experiences in the context of BDTD. Concludes that

\footnotetext{
${ }^{1}$ A primeira versão desta pesquisa foi apresentada de forma oral na Conferência sobre Tecnologia, Cultura e Memória realizada no Instituto Ricardo Brennand, Pernambuco em novembro de 2013.
} 
digital memory is very important to safeguard all the necessary material, thus preventing damage that may jeopardize information and memory, making it accessible to all posterity, and that BDTD UFRN is an essential tool for preserving the university scientific memory.

Keywords: Preservation of memory. Digital memory. Biblioteca Digital de Teses e Dissertações - UFRN.

\section{INTRODUÇÃO}

A cultura de um povo, seus costumes e valores são construídos ao longo do tempo e isso faz cada povo ser único, com uma matriz de identidade própria que o difere das demais sociedades. Porém, para que se possa compreender a cultura e a história de um povo e para que cada indivíduo inserido nela se compreenda como parte deste, se faz necessário que se conheça a história que os moldou. O papel da memória é fazer com que a sociedade compreenda, através do passado, o seu presente, reconhecendo-se em um grupo e, consequentemente, se adequando a novas realidades.

Em contrapartida, no mundo em que se vive hoje, é diariamente produzida uma enorme quantidade de informações, as quais são registradas e disseminadas nos mais variados suportes e formatos. Por consequência de fatores como o crescimento demográfico, uma maior facilidade à educação e às tecnologias, o desenvolvimento de várias regiões e grupos sociais e a revolução tecnológica dos últimos 20 anos, muito provavelmente as gerações atuais produzem e registram mais informação que toda informação registrada por milhares de gerações que as antecederam (FERREIRA, M., 2006).

Desta forma, preservar a memória não seria algo tão simples sem ajuda das praticidades tecnológicas. Sendo assim, uma parte considerável desta informação é produzida, registrada e disseminada em suportes digitais, uma vez que estes apresentam vantagens como a facilidade na partilha de informação, a economia de tempo e espaço e a possibilidade de manter cópias de segurança sem grandes transtornos. 
No âmbito acadêmico do Rio Grande do Norte, uma personagem que merece destaque é a Biblioteca Digital de Teses e Dissertações (BDTD) da Universidade Federal do Rio Grande do Norte (UFRN), que objetiva disponibilizar, via internet, as teses e dissertações produzidas no contexto da UFRN, proporcionando, desta maneira, maior visibilidade nacional e internacional às produções da universidade potiguar, bem como democratização em relação ao acesso ao conhecimento.

A partir deste posicionamento, surge o objetivo geral deste artigo, que é realizar algumas reflexões a partir de revisão de literatura sobre a BDTD, e o objetivo específico, o qual é mostrar a importância da BDTD - UFRN para a preservação da memória científica da Instituição.

A metodologia escolhida para dar embasamento ao trabalho foi a revisão bibliográfica e eletrônica, bem como experiências empíricas no contexto da BDTD. E, em relação à relevância desta pesquisa, pode-se dizer que ela possui destaque por contribuir para todos os profissionais da área ligados à Biblioteconomia, principalmente no que se trata de preservação da memória em espaço digital, dando ênfase no contexto norte-rio-grandense, tomando como referência a biblioteca digital da UFRN.

\section{A IMPORTÂNCIA DE SE PRESERVAR A MEMÓRIA}

Para que seja possível compreender o presente, faz-se necessário primeiro conhecer o passado e os processos sociais e culturais que ocorreram no decorrer dos tempos. Conhecendo-se o passado e a história das culturas, o indivíduo torna-se mais preparado a adequar-se a novas realidades, na medida em que se conhece dentro de um contexto cultural construído durante a história. Portanto é fundamental que a memória seja preservada para que possa ser repassada às futuras gerações.

A fim de entender mais profundamente o que é preservação e memória, observam-se seus conceitos oferecidos por alguns autores da área.

Para Conway (1997, p. 14):

Preservação é uma palavra que envolve inúmeras políticas e opções de ação, incluindo tratamentos de conservação. Preservação é a aquisição, organização e distribuição de recursos, a fim de impedir posterior deterioração ou renovar a possibilidade de utilização de um seleto grupo de materiais. 
Segundo Ferreira, A. (2013, Não paginado) é a "faculdade pela qual o espírito conserva ideias ou imagens, ou as readquire sem grande esforço; faculdade de reter ideias, sensações, impressões, adquiridas anteriormente; recordação que a posterioridade guarda". Outra definição é que a "memória é a capacidade que certos seres vivos têm em armazenar, no sistema nervoso, dados ou informações sobre o meio que os cerca, para assim modificar o próprio comportamento" (CHAPOUTHIER, 2006 apud RUEDA; FREITAS; VALL, 2006, p. 80).

Enquanto fenômeno social, memória significa um processo histórico e tradicional pelo qual se observa e analisa características culturais de um povo específico. Ela pode ser coletiva, quando faz parte de um grupo de pessoas, ou individual, quando faz parte de uma pessoa apenas. A identidade de um povo é construída através da sua memória coletiva, da história preservada dos antepassados e do conhecimento produzido durante os séculos. Observa-se, então, que a preservação dos artefatos que representam a história e a cultura de uma sociedade tem a função de assegurar a memória, levando em conta que esta é o único meio de conhecer o passado no presente.

Os suportes memoriais são os monumentos, os livros, as esculturas, as estruturas arquitetônicas de um lugar e tantos outros. Com a era tecnológica, surge o suporte digital, sobre o qual se falará adiante.

\subsection{MEMÓRIA DIGITAL}

A preservação digital, um dos meios de se guardar a memória, é o conjunto de atividades ou processos responsáveis por garantir o acesso contínuo a longo-prazo à informação e a todo patrimônio cultural existente em formatos digitais. Ela consiste na capacidade de garantir que a informação digital permaneça acessível e com qualidades de autenticidade suficientes, com a finalidade de ela poder ser interpretada no futuro ao se recorrer a uma plataforma tecnológica diferente da utilizada no momento da sua criação.

Com a revolução digital, os suportes para armazenar a memória estão cada vez mais práticos, compactos e seguros. Com o avanço das tecnologias dispõe-se de 
plataformas (hardwares e softwares), que armazenam, processam e transmitem as informações ali guardadas.

Conta-se também com a chamada computação nas nuvens, a qual possibilita acessar arquivos e executar diferentes tarefas na internet, pois os dados se encontram na rede e não em um computador especifico. Basta apenas estar conectado ao serviço online e o arquivo pode ser acessado de qualquer lugar. Podem-se citar alguns exemplos como o Dropbox, e-mails e até mesmo as redes sociais.

Além de sua praticidade, os suportes digitais tornam-se cada vez mais seguros e buscam maneiras de conservar e proteger os registros de memória, aspirando que as gerações futuras tenham acesso à história e à cultura de uma determinada época e sociedade, pois se entende que essas memórias ajudaram a formar a identidade das novas gerações.

$\mathrm{Na}$ academia, surgiu a necessidade de um meio digital que pudesse armazenar trabalhos científicos, de modo que estes pudessem ser além de preservados, disseminados para a sociedade, em prol da democratização da informação científica. Pensando nisto, foram criados repositórios institucionais e as bibliotecas digitais, onde são disponibilizados artigos científicos, monografias, dissertações e teses, entre outros documentos.

As bibliotecas digitais são importantes instrumentos de disseminação do conhecimento científico, além de um meio de preservação da memória. Neste contexto, cabe enfatizar o conceito de biblioteca digital.

\subsection{BIBLIOTECA DIGITAL}

A fim de se compreender o que é biblioteca digital (BD), precisa-se, antes mesmo de conhecer seus conceitos, entender como se deu seu surgimento.

A existência das bibliotecas digitais pode ser considerada como a evolução da utilização dos sistemas de recuperação de dados, os quais remontam aos anos 70 , assim como do uso de sistemas de hipertexto que teve início nos anos 80 . Apesar de seu início datar na década de 90, já existia indícios quase proféticos de sua futura criação quando Vannevar Bush idealizou, em 1945, uma máquina denominada Memex. Esta criação possibilitaria o armazenamento de textos e imagens, possibilitando a 
associação entre eles. Esta máquina visionária pode ser percebida como uma espécie de projeto embrionário das BDs. Porém, somente depois do surgimento da era digital e do advento da internet, que foi possível tornar a BD em uma realidade.

A Biblioteca Digital surge em um momento em que há a crescente necessidade de organizar, guardar e disseminar toda a informação produzida. Muitos estudiosos buscaram conceituar a BD, e o conhecimento de alguns destes conceitos são de fundamental importância para a compreensão e caracterização deste meio informacional.

Há diversas nomenclaturas dadas a este tipo de biblioteca, como por exemplo biblioteca eletrônica, biblioteca virtual e até mesmo biblioteca sem paredes. Portanto, todas essas nomenclaturas são remetidas a um só conceito. Bax (1997) define este tipo de biblioteca como sendo:

[...] entidades capazes de vencer as limitações naturais, espaço-temporais, impostas a objetos físicos (livros, estantes, salas, prédios), permitindo novas práticas de trabalho e oportunidades. [...] Uma biblioteca digital completa deve ser capaz de oferecer todos os serviços essenciais de uma biblioteca tradicional, assim como explorar as bem conhecidas vantagens do estoque, pesquisa e comunicação digital. (BAX, 1997, p. 2)

Desta forma, a Biblioteca Digital para ser completa, deve oferecer todos os serviços disponíveis na Biblioteca tradicional, e não apenas disponibilizar o material para consulta.

Outra definição dada a este tipo de instituição é a de Leiner (1998) o qual afirma que a biblioteca Digital é a coleção de serviços e objetos de informação disponibilizados em meio digital, tendo sua organização, estrutura e apresentação capacidade de suportar a comunicação dos usuários com os objetos informacionais.

Para Marcondes et al (2005) a Biblioteca Digital tem como base de acervo textos em formatos digitais, periódicos, livros, imagens, teses e dissertações, entre outros tipos informaconais. Esses documentos são disponibilizados seguindo processos padronizados em acesso on line.

Nota-se, com os conceitos supracitados, que a BD é um ambiente onde podem ser armazenadas informações variadas. Em outras palavras, a biblioteca eletrônica é um conjunto de coleções disponibilizadas em rede, as quais podem ser transferidas 
para o computador dos usuários através de downloads, fazendo com que estes leitores economizem esforços, tornando mais ágil o processo de busca.

E suma, a BD surgiu da prática já existente de importar as informações para base de dados. Desta forma, é possível afirmar que desde a sua criação, a biblioteca digital interage com os diversos tipos de tecnologias, as quais dinamizaram ainda mais a busca da informação, além de torná-la mais acessível. Neste sentido, visa-se aprofundar um pouco mais o conhecimento de um dos diversos tipos de biblioteca digital, a Biblioteca Digital de Teses e Dissertações, que se terá conhecimento a seguir.

\section{UM BREVE HISTÓRICO SOBRE A BDTD}

O Consórcio Brasileiro de Teses e Dissertações, formado pelas instituições de ensino e pesquisa que compõem a rede de informações da BDTD foi criado em abril de 2002, com base em um estudo de 2001, coordenado pelo Instituto Brasileiro de Informação em Ciência e Tecnologia (IBICT), do qual fizeram parte, especialistas do próprio IBICT, do Conselho Nacional de Desenvolvimento Científico e Tecnológico (CNPq), da Universidade de São Paulo (USP), da Pontífica Universidade Católica do Rio de Janeiro (PUC-Rio), da Universidade Federal de Santa Catariana (UFSC) e da Biblioteca Regional de Medicina (Bireme), além de consultores contratados.

A partir desse estudo foi criado um projeto piloto, em que três das universidades integrantes do grupo de estudo (PUC-Rio, USP e UFSC) enviaram amostras dos metadados das teses e dissertações publicadas em seus repositórios, segundo padrão preestabelecido pelo grupo de estudos. Esse projeto-piloto comprovou a viabilidade da implantação da solução proposta e estabeleceu o Padrão Brasileiro de Metadados de Teses e Dissertações (Mtd-Br).

Em abril de 2003, foi concluída a primeira versão do Sistema de Publicação de Teses e Dissertações (TEDE), desenvolvida pelo IBICT com o objetivo de auxiliar as instituições de ensino e pesquisa na implantação de suas próprias bibliotecas digitais, que ocorreu experimentalmente em quatro instituições: a Universidade Federal Fluminense (UFF), a Universidade Católica de Brasília (UCB), a Universidade Federal de Brasília (UnB) e a Universidade Federal do Ceará (UFC). A experiência comprovou a eficácia do sistema e ajudou a subsidiar ações de implantação desse sistema em nível 
nacional. Atualmente, o TEDE está disponível para download no site http://tedesite.ibict.bre é distribuído pelo IBICT gratuitamente.

Utilizando a tecnologia do Open Archive Initiative (AOI), o IBICT atua como um agregador de dados, para disponibilizar nacionalmente as informações contidas nas teses e dissertações abrigadas nas BDTDs afiliadas de instituiçoes por todo o país. $O$ papel do IBICT nessa parceria (além de servir como agregador e ferramenta de busca) é fornecer apoio técnico para gestão e operação dos repositórios digitais das instituições de pesquisa e universidades associadas (que atuam como provedores de dados), e também disponibilizar esses materiais informacionais para outros sistemas, como a Networked Digital Library of Theses and Dissertation (NDLTD), da Virginia Tech University. (INSTITUTO DE INFORMAÇÃO EM CIÊNCIA E TECNOLOGIA, 2013a)

E, de acordo com o Instituto de Informação em Ciência e Tecnologia (2013b, não paginado):

A Biblioteca Digital Brasileira de Teses e Dissertações (BDTD) tem por objetivo integrar, em um único portal, os sistemas de informação de teses e dissertações existentes no país e disponibilizar para os usuários um catálogo nacional de teses e dissertações em texto integral, possibilitando uma forma única de busca e acesso a esses documentos.

Observa-se, assim, a grande importância que a BDTD possui em relação à democratização do conhecimento, assim como com a disseminação das teses e dissertações do país.

\subsection{BDTD DA UFRN E A PRESERVAÇÃO DA MEMÓRIA DIGITAL}

No contexto do Rio Grande do Norte, há a Biblioteca Digital de Teses e Dissertações da UFRN, a qual iniciou em 2006, quatro anos após a fundação da BDTD no Brasil. A Biblioteca Central Zila Mamede (BCZM) é a responsável por alimentar o sistema e seu banco de dados, disponibilizando os trabalhos via internet em formato .pdf, possibilitando o download, impressão e leitura.

A BDTD é um espaço virtual que favorece a democratização da informação de trabalhos de pós-graduação de mestrandos e doutorandos da UFRN para toda a 
comunidade, visando contribuir para disseminação do conhecimento, reduzindo possíveis barreiras referentes a motivos financeiros, de tempo e/ou espaço.

O processo de recebimento, tratamento e disponibilização dos documentos seguem o procedimento a seguir: as teses e dissertações na versão impressa chegam à BCZM em tempo irregular, porém, constante, ou seja, não há uma data precisa para que estas cheguem à biblioteca. São enviadas pela Pró-Reitoria de Pós-Graduação da universidade, e chegam armazenadas em caixas, nas quais se encontram também os arquivos em CD, os termos de autorização de cada documento e uma listagem constando os itens enviados.

Em seguida, acontece o processo de organização dos arquivos, que consiste na separação dos termos, CDS e documentos impressos por cursos de pós-graduação, contando-os e verificando se a contagem é compatível com a quantidade discriminada na listagem.

Após a separação e contagem, os arquivos em CDs são baixados no sistema de computador, o Apus, e colocados em pastas organizadas por centros e cursos. Depois deste processo, verificam-se os arquivos que, porventura, vierem com partes faltando, como folha de rosto, ficha catalográfica ou folha de aprovação da banca examinadora. Faltando uma destas partes, é procurada no trabalho impresso e digitalizada para inclusão no trabalho digital.

O próximo passo é distribuir as teses para o setor de catalogação, que irá incluílo na base de consultas bibliográficas no Sistema Integrado de Gestão de Atividades Acadêmicas (SIGAA), software utilizado para questões acadêmicas e administrativas da UFRN, e colocados no setor de Coleções Especiais, onde estarão disponíveis para consultas.

Após esta etapa, os arquivos digitais são disponibilizados na base de dados da BDTD, podendo ser, de acordo com a autorização dos autores, visualizados parcialmente ou totalmente.

Todo o processo é feito de forma cuidadosa para que nenhuma informação seja distorcida ou omitida. A BDTD da UFRN ocupa o 11ำ lugar, das 96 BDTDs existentes no Brasil, no ranking nacional de teses e dissertações publicadas, com o número de 8368 trabalhos disponibilizados. (INSTITUTO BRASILEIRO DE INFORMAÇÃO EM CIÊNCIA E TECNOLOGIA, 2013c) 
Esta biblioteca digital, além de ser um lugar de disseminação de conhecimentos, também é uma importante ferramenta de preservação do meio digital, uma vez que reúne tais documentos e os perpetuam para posteridade.

Em relação à migração de um documento impresso para o digital, Arellano (2008, p. 22) explica que:

A maioria dos bibliotecários e arquivistas aceita que a preservação digital depende de modo geral da migração de material digital que permite que ele seja compatível com novas tecnologias. Mas a migração é muito mais complexa do que apenas transferir o Bitstream de uma mídia para outra. A estrutura interna e o conteúdo do material devem ser preservados e transferidos igualmente, para que, dessa forma, o "novo" objeto seja uma representação fiel do original.

A migração de material impresso para o material digital deve ocorrer de forma que assegurem a informação contida no primeiro meio, sendo fiel a esta.

A preservação da informação em meio digital possibilita uma maior durabilidade dos conteúdos informacionais de documentos, já que os suportes analógicos como o papel possuem uma propensão maior a se desgastarem devido a problemas de ordem físicas, químicas e biológicas. O meio digital é uma alternativa mais segura para a manutenção de tais documentos informacionais, e principalmente, vai focar na preservação da informação em si. Seu conteúdo vai ser primordialmente conservado, e não mais o suporte físico. A disponibilização para o uso em meio digital é mais viável, pois mantém a integridade do material impresso, sem pô-lo em risco constante de degradação.

De acordo com Cunha (2009, p.143):

O acúmulo de informação e conhecimento vai aos poucos construindo a memória, que começa a ser preservada sob o paradigma custodial, baseada no acúmulo e guarda. Tal preservação se encontra redimensionada com o surgimento e utilização das novas tecnologias de informação. Neste novo contexto, a preservação da memória deve vislumbrar como estratégia não só o armazenamento, mas também a promoção de seu uso, para que se perpetue através de outros registros.

Nota-se, portanto, que a Biblioteca Digital da UFRN é um ambiente que torna disponível o acesso ao conhecimento de trabalhos científicos dos acadêmicos da instituição, porém sua missão vai além da democratização destes. É, sobretudo, uma 
ferramenta de preservação do patrimônio intelectual da universidade norte-riograndense. Nesta perspectiva, cabe ressaltar também que atualmente uma outra personagem vem ganhando destaque no que diz respeito à preservação da memória e à disseminação da produção científica: o Repositório Instituicional (RI). E, como daqui a alguns anos, o espaço da BDTD será "cedido" ao RI, será abordado a seguir alguns aspectos relevantes sobre este tipo de estratégia que dará prosseguimento à missão da BDTD.

\section{O FUTURO DA BDTD}

Antes de tudo, é necessário esclarecer a diferença entre biblioteca digital e repositório instituicional. A primeira, de acordo com o que já foi discutido, diz respeito apenas à organização de documentos em formato digital, visando a conservação e a distribuição da informação. Trata-se de coleções de documentos digitais armazenados em um servidor e gerenciados por algum software destinado a este fim. Já o segundo vai mais além. Ele preconiza a filosofia da Iniciativa dos Arquivos Abertos (OAI Archives Intiative), a qual "defende que todos os materiais de pesquisa devem estar disponibilizados publicamente na Web, sem restrições de acesso" (SANTOS JÚNIOR, 2010, p. 35).

Além disso, ele constitui um serviço de informação científica - em espaço digital e interoperável - que objetiva gerenciar a produção acadêmica de uma instituição, contemplando reunião, armazenamento, organização, preservação, recuperação e, acima de tudo, ampla disseminação da informação produzida pelas instituições científicas e acadêmicas. Assim, percebe-se que todo repositório institucional é uma biblioteca digital. Mas nem toda biblioteca digital é um repositório institucional. (INSTITUTO BRASILEIRO DE INFORMAÇÃO EM CIÊNCIA E TECNOLOGIA, 2012d).

Em relação à implementação de um $\mathrm{RI}$, encontra-se uma estrutura hierarquizada, com acesso via web e com metadados coletados através do protocolo OAI-PMH (mecanismo que permite a transferência de dados em bibliotecas digitais), fazendo com que seja possível que os usuários, ao utilizarem qualquer ferramenta de busca dentro da iniciativa dos arquivos abertos, possam encontrar e recuperar o conteúdo do repositório. 
Sobre os softwares mais utilizados nos dias de hoje no contexto dos repositórios institucionais, encontram-se o EPrints e o DSpace.

O Eprints foi desenvolvido pela University of Southampton e permite o depósito de trabalhos que ainda não foram publicados (pré-prints), trabalhos já publicados (pósprints) e outros tipos de publicações, comentários e versões, assim como outros tipos de documentos.

O DSpace, por sua vez, foi desenvolvido pelo Massachusetts Institute of Technology Libraries e pelos Laboratórios Hewlett-Packard para criação de RI multidiciplinares para bibliotecas, arquivos e centros de pesquisa. Sua estrutura abarca um modelo de informação organizacional que toma por base "comunidades" e coleções. Tem suporte para os mais variados tipos de formatos de arquivos digitais, tais como textos, som e imagem.

Os dois sistemas, o Eprints e o Dspace, são apropriados para a criação e manutenção de repositórios digitais e ambos estão configurados para tornar viável a interoperabilidade com outros sistemas de publicação e armazenamento de documentos em formato digital. (VIANA; ARELLANO, 2013). Além disso, um ponto relevante sobre estas ferrmentas é a questão de elas se basearem no princípio de que o próprio autor realize seu depósito (autoarquivamento). Muitas instituições já aderiram ao uso de um dos softwares e, consequentemente, à ideia de repositórios instituicionais. A escolha por qual deles usar dependerá das políticas institucionais existentes para saber qual será o mais adequado.

A UFRN, inclusive, está passando atualmente por uma transição da BDTD para a utilização do RI, através do DSpace. No entanto, isso não desmerece o que a BDTD da Universidade representou e ainda representa para a preservação da produção acadêmica da instituição.

O que tudo isso mostra é que novos tipos de tecnologias vêm sendo implementadas no que diz respeito à preservação da memória, aperfeiçoando-se e buscando estratégias cada vez mais viáveis para facilitar o gerenciamento e a disseminação daquilo que mais importa no meio científico e acadêmico: a informação. 


\section{CONSIDERAÇÕES FINAIS}

Percebe-se, a partir do que se desprende desta pesquisa, que as informações e os conhecimentos reunidos durante determinado tempo são o que formam a memória, e sua preservação é o que irá resguardar a história da humanidade. Com o surgimento das tecnologias digitais de informação, tal preservação toma um novo rumo, trazendo novos meios e técnicas para eternizar a informação.

Neste sentido, cumpre frisar que a BDTD é uma rede excelente de preservação do patrimônio acadêmico, tanto no meio digital quanto em relação a seu suporte analógico, uma vez que evita que o impresso seja manuseado várias vezes, desgastando sua estrutura física. Além disso, a BDTD é um forte meio de disseminação do conteúdo informacional advindo da área científica da universidade, contribuindo para o desenvolvimento cultural e intelectual da sociedade como um todo.

É importante ressaltar que a Biblioteca Digital veio somar no que tange a agregação de conhecimento e cultura, sendo esta um instrumento que se torna cada vez mais necessário nas universidades, por seu caráter democrático que favorece a todos o acesso à informação cientifica, bem como promove o intercâmbio de informações.

Percebe-se também a importância que a BDTD assume no que se refere, primordialmente, à memória, uma vez que ela assume a responsabilidade de não somente disseminar mais facilmente as informações, através da facilidade que seu acesso evoca, mas, sobretudo, de salvaguardar o conhecimento adquirido pelo homem ao longo de sua história.

A BDTD da UFRN trata-se de um meio acessível que promove o conhecimento registrado de teses e dissertações de forma eficiente, derrubando as barreiras de espaço e de ordem financeira existentes, tornando acessível o conhecimento científico da UFRN e o preservando para a posteridade.

É importante salientar também que, nos dias atuais, novos tipos de ferramentas vêm ganhando espaço no contexto do armazenamento e da disseminação da produção acadêmica, tendo como foco, sempre, a preservação da memória instituicional, uma vez que, conforme a sociedade vai evoluindo e novas demandas vão surgindo, há 
inevitavelmente o aperfeiçoamente de estratégias e mecanismos já existentes ou a criação de novos para melhor atendimento a determinadas atividades.

No entanto, de acordo com o que foi explanado, a BDTD não perde a representatividade que possui e ainda terá por um bom tempo no que tange a sua relevância para a memória institucional da UFRN.

\section{REFERÊNCIAS}

ARELLANO, Miguel Ángel Márdero. Critérios da preservação digital da Informação científica. 2008. 354 p. Tese (Doutorado em Ciência da Informação) - Programa de PósGraduação em Ciência da Informação, Universidade de Brasília, Brasília, 2008.

Disponível em:

<http://bdtd.bce.unb.br/tedesimplificado/tde_busca/arquivo.php?codArquivo=4547>. Acesso em: 09 jun. 2013.

BAX, Marcelo Peixoto. Agentes de Interface para Bibliotecas Digitais: A Arquitetura SABiO. In: Seminário Sobre Automação em Bibliotecas e Centros de Documentação, 6., 1997, Águas de Lindóia. Anais... Águas de Lindóia: UNIVAP, 1997.

CONWAY, Paul. Preservação no Universo Digital. Rio de Janeiro: Projeto Conservação Preventiva em Bibliotecas e Arquivos, 1997.

CUNHA, Jacqueline de Araújo. Bibliotecas digitais de teses e dissertações: uma estratégia de preservação da memória. 2009. 141 p. Dissertação (Mestrado em Ciência da Informação) - Programa de Pós-Graduação em Ciência da Informação, Universidade Federal da Paraíba, João Pessoa, 2009. Disponível em <

http://bdtd.biblioteca.ufpb.br/tde_busca/arquivo.php?codArquivo=987 >. Acesso em: 25 out. 2013.

INSTITUTO BRASILEIRO DE INFORMAÇÃO EM CIÊNCIA E TECNOLOGIA. O que é a BDTD. Disponível em: <http://bdtd.ibict.br/pt/a-bdtd.html?showall=1>. Acesso em 20 set. 2013a.

INSTITUTO BRASILEIRO DE INFORMAÇÃO EM CIÊNCIA E TECNOLOGIA. Biblioteca Digital de Teses e Dissertações (BDTD). Disponível em: <http://www.ibict.br/informacaopara-ciencia-tecnologia-e-inovacao\%20/biblioteca-digital-Brasileira-de-teses-edissertacoes-bdtd/apresentacao>. Acesso em: 13 jun. 2013b.

FERREIRA, Aurélio Buarque de Holanda. Dicionário do Aurélio Online. Disponível em: <http://www.dicionariodoaurelio.com/Memoria.html>. Acesso em: 31 jul. 2013.

FERREIRA, Miguel. Introdução à preservação digital: conceitos, estratégias e actuais consensos. Guimarães, Portugal: Escola de Engenharia da Universidade do Minho, 2006. Disponível em: <http://eprints.rclis.org/8524/1/livro.pdf>. Acesso em: 29 jul. 2013. 
INSTITUTO BRASILEIRO DE INFORMAÇÃO EM CIÊNCIA E TECNOLOGIA. Série históricas por instituições de defesa: resumo. Disponível em < http://bdtdj.ibict.br/indicadores/graficoRS.jsp? $\operatorname{cod} 1=\& \operatorname{cod} 2=\& \operatorname{cod} 3=>$ Acesso em: 23 set. 2013c.

INSTITUTO BRASILEIRO DE INFORMAÇÃO EM CIÊNCIA E TECNOLOGIA. Boas práticas para a construção de repositórios institucionais da produção científica. Brasília: IBICT, 2012d.

LEINER, Barry M.. Metrics and digital libraries. D-Lib Magazine, jul./ago.1998

MARCONDES, Carlos $\mathrm{H}$. et al. Bibliotecas digitais: saberes e práticas. Brasília: EDUFBA, 2005.

RUEDA, Valéria Matias da Silva; FREITAS, Aline de; VALLS, Valéria Martin. Registros evolutivos. Viver Mente \& Cérebro: Memória, n.2, p. 78 - 89, jul. 2006. Ed. Especial.

SANTOS JÚNIOR, Ernani Rufino dos. Repositórios Institucionais de acesso livre no Brasil: estudo delfos. 2010. 177p. Dissertação (Mestrado em Ciência da Informação) Programa de Pós-Graduação em Ciência da Informação, Universidade de Brasília, Brasília, 2010. Disponível em

<http://bd.camara.gov.br/bd/bitstream/handle/bdcamara/8988/repositorios_institucionais _santosjssant.pdf?sequence=1>. Acesso em: 25 out. 2013.

VIANA, Cassandra Lúcia de Maya; ARELLANO, Miguel Ângelo Márdero. Repositórios Institucionais baseados em DSpace e EPrints e sua viabilidade nas instituições acadêmico-científicas. Disponível em < <http://eprints.rclis.org/8834/1/Trabalho_SNBU_RI_DSpace_EPrints_IES.pdf > . Acesso em: 23 out. 2013. 